\title{
Studies on Tissue Specificity of Interferon
}

\author{
By BARBARA P. RILEY AND G. E. GIFFORD \\ Department of Microbiology, College of Medicine, \\ University of Florida, Gainesville, Florida, U.S.A.
}

(Accepted for publication 12 September 1966)

\begin{abstract}
SUMMARY
This study reports the investigation of tissue specificity of interferon induced with Chikungunya virus in lung and kidney cells obtained from 17-day chick embryos. Lung cells produced significantly more interferon than kidney cells under essentially the same conditions. Both lung and kidney interferon preparations repressed plaque formation on homologous and heterologous cells and lung cells were more sensitive to the protective effects of all the interferon preparations tested. No evidence for tissue specificity was obtained.
\end{abstract}

\section{INTRODUCTION}

Since the original observation that the cell which produces an interferon governs its specificity of action (Tyrrell, 1959), species specificity has become a well-documented property of interferon. However, no systematic study has been done to determine whether interferon made in different tissues obtained from the same animal exhibits tissue specificity. If tissue specificity is a property of interferon, this would be important in the understanding of interferon action, as well as in its use as a therapeutic agent. It would also imply that more than one cistron could be responsible for interferon synthesis. This study reports the investigation of tissue specificity of interferon induced in freshly dispensed lung and kidney cells obtained from 17-day chick embryos. Chick lung and kidney tissues differ in their embryonic origin. The kidney arises entirely from the mesodermal layer. The lung originates mainly from the endoderm, although the mesoderm makes some contribution to the connective elements and musculature of the lung.

\section{METHODS}

Cell cultures. Chick embryo fibroblast (CEF) cell cultures prepared from eviscerated and decapitated 10- to 11-day chick embryos were used for assay of virus and interferon (Lindenmann \& Gifford, 1963a). Chick embryo lung and kidney cells, used for interferon production and assay, were prepared from 17-day chick embryos by a slight modification of the procedure used for whole embryos. The trypsin (Trypsin 1:250; Difco Laboratories, Detroit, Michigan, U.S.A.) used to prepare these cultures was increased to $0.1 \%(\mathrm{w} / \mathrm{v})$ for kidney cells, and $0.25 \%(\mathrm{w} / \mathrm{v})$ for lung cells. In culture, lung tissue was composed of $67 \%$ fibroblast-like cells and $33 \%$ epithelium-like cells; kidney tissue was composed of $80 \%$ epithelium-like cells and $20 \%$ fibroblast-like cells. Chick embryo fibroblast cell cultures were used at $44-48 \mathrm{hr}$; lung and kidney cells were used immediately after dispensing for interferon production, or at $27 \mathrm{hr}$ 
for interferon assays. The monolayers of all three cell types contained approximately $4 \times 10^{6}$ cells at the time of use.

Media. Growth medium consisted of Gey's BSS with $5 \%$ (v/v) calf serum, $0 \cdot 1 \%$ (w/v) lactalbumin hydrolysate (enzymic; General Biochemicals, Chagrin Falls, Ohio, U.S.A.), $0.1 \%$ (w/v) Proteose peptone (Difco Laboratories), and $0.0025 \mathrm{M}$-tris or $0.06 \%(\mathrm{w} / \mathrm{v})$ sodium bicarbonate. Maintenance medium was Gey's BSS with $0.11 \%$ $(\mathrm{w} / \mathrm{v})$ sodium bicarbonate, $0.1 \%(\mathrm{w} / \mathrm{v})$ lactalbumin hydrolysate, $0.1 \%(\mathrm{w} / \mathrm{v})$ yeast extract (Difco Laboratories) and $0.1 \%$ (w/v) Proteose peptone (Gifford, Mussett \& Heller, 1964). Trypsin diluent consisted of Gey's BSS without magnesium and calcium. The medium used for the agar overlay consisted of maintenance medium with a final concentration of $5 \%(\mathrm{v} / \mathrm{v})$ calf serum and $0.5 \%(\mathrm{w} / \mathrm{v})$ 'Ion-agar' no. 2, omitting the yeast extract.

Virus strains. Vesicular stomatitis virus (VSV: Indiana strain) obtained from Dr S. Baron (National Institutes of Health, Bethesda, Maryland, U.S.A.) and vaccinia virus strain NY-914, were used for interferon assays. Stock preparations of VSV were derived by passage in primary cultures of chick embryo fibroblasts. Stock vaccinia virus was prepared by inoculating the chorioallantois of 11-day developing chick embryos. Infected membranes were removed and homogenized in maintenance medium $48 \mathrm{hr}$ after inoculation. Chikungunya virus, used as the interferon inducer, was prepared by passage in the brains of new born mice. Brains were removed 44 $48 \mathrm{hr}$ after inoculation and homogenized in maintenance medium to make a $10 \%$ $(\mathrm{w} / \mathrm{v})$ suspension. All virus stocks were centrifuged to remove tissue debris and were stored in glass ampoules at $-70^{\circ}$.

Interferon. Chick lung and kidney interferon was induced in kidney and lung cells by adding a 1/100 dilution of stock Chikungunya virus at the time the cells were dispensed. One hundred million $\left(10^{8}\right)$ kidney and lung cells in $20 \mathrm{ml}$. growth medium were dispensed into $32 \mathrm{oz}$. bottles with a flat surface of $17 \times 7 \mathrm{~cm}$. Interferon-containing supernatant fluids were harvested $20 \mathrm{hr}$ later. Chikungunya virus was inactivated by heating at $65^{\circ}$ for $30 \mathrm{~min}$. Interferon assays in which vaccinia virus was used as challenge virus followed the procedure of Lindenmann \& Gifford (1963b). For interferon assays with VSV as challenge virus, cells were treated with the desired interferon dilutions for 6-7 hr before challenge with VSV. Virus was allowed to adsorb for $1 \mathrm{hr}$, unadsorbed virus was removed, and an agar-overlay added. In both systems, one p.d.d. 50 unit is the amount of interferon which depressed the plaque count by $50 \%$ (Lindenmann \& Gifford, 1963b).

\section{RESULTS}

Production of interferon by kidney and lung cells

Low yields of interferon were detectable in the supernatant fluids of kidney and of lung cell cultures within $1 \mathrm{hr}$ after infection with Chikungunya virus. Production continued linearly for about $20 \mathrm{hr}$. when a maximum titre was reached. Interferon was produced at a faster rate and reached a significantly higher titre in lung than in kidney cultures. Statistical analysis of differences between titres obtained at the point of maximum production in each system revealed that these differences were significant at the $1 \%$ level, or that they would be obtained by chance only 1 in 100 times (See Table 1). The method for interferon induction was identical in both systems, indicating 


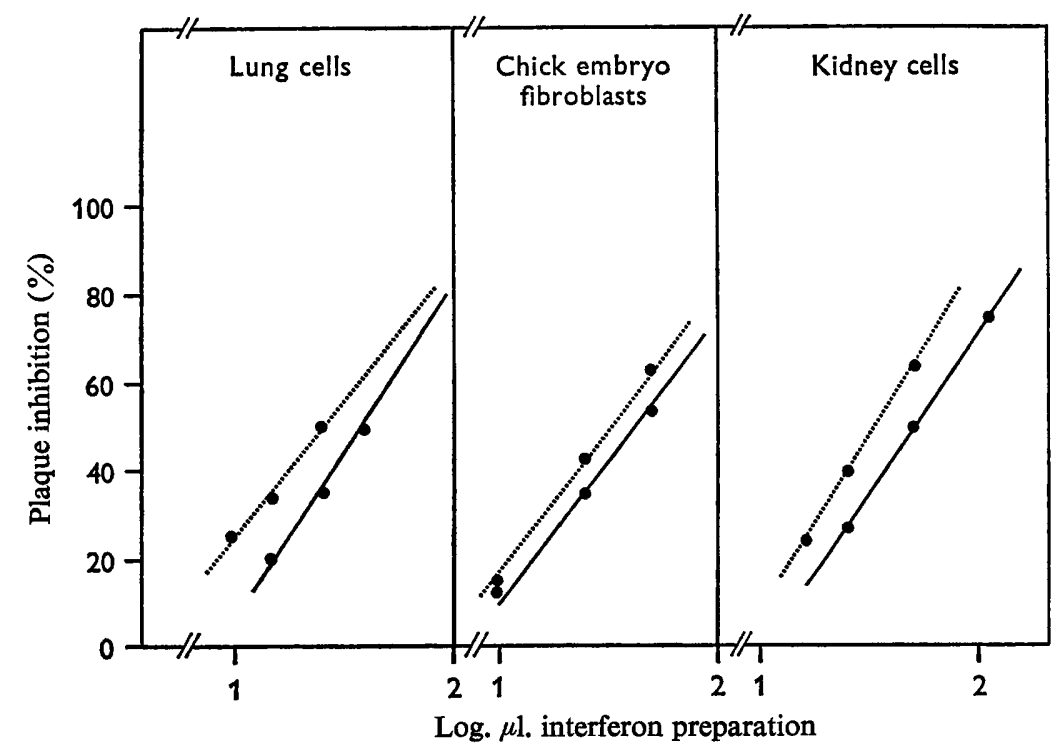

Fig. 1. Dose response curves of interferon prepared in kidney and lung cells on vesicular stomatitis virus plaque formation on lung, kidney and chick embryo fibroblast cultures. - , Kidney interferon; ......, lung interferon.

Table 1. Comparison of lung and kidney interferon assayed on chick embryo fibroblast cultures*

\begin{tabular}{ccc}
$\begin{array}{c}\text { Preparation } \\
\text { no. }\end{array}$ & $\begin{array}{r}\text { Activity of interferon preparations, } \\
\text { p.d.d. } 50 \text { units/ml. }\end{array}$ \\
\cline { 2 - 3 } 1 & $\begin{array}{c}\text { Lung interferon } \\
\text { Kidney interferon }\end{array}$ \\
2 & 345 & 116 \\
3 & 208 & 109 \\
3 & 169 & 54 \\
200 & 61
\end{tabular}

* Vaccinia virus challenge, The difference between p.d.d. 50 units for lung and kidney interferon preparations was significant to the $1 \%$ level.

that the greater yield of interferon from the lung system could probably be attributed to some property of the lung cells themselves. A difference in the capacity of cells to synthesize and release interferon was reported by Ho (1964).

Tissue specificity assays

Dose-response curves depicting the effect of kidney and lung interferon on VSV plaque formation on lung, kidney, and CEF monolayers are shown in Fig. 1. As expected from the titre of interferon on CEF cultures infected with vaccinia virus, interferon from lung cell cultures afforded significantly greater protection in all systems than did interferon obtained from kidney cells. Lung cultures were also more sensitive to interferon action than were kidney or CEF cultures. This greater sensitivity 
was found even when interferon made in kidney cultures was used. p.d.d.50 units were determined by interpolation, converted to units per ml. and are reported in Table 2.

Table 2. Comparison of p.d.d.50 units of interferon preparations produced and assayed in various systems*

p.d.d. 50 units $/ \mathrm{ml}$. of interferon

\begin{tabular}{|c|c|c|c|c|}
\hline \multirow[b]{2}{*}{ Interferon producing system } & \multirow[b]{2}{*}{ Prep no. } & \multicolumn{3}{|c|}{ Interferon assay system on } \\
\hline & & Lung & Kidney & $\begin{array}{l}\text { chick embryo } \\
\text { fibroblasts }\end{array}$ \\
\hline Lung & $\begin{array}{l}1 \\
2 \\
3\end{array}$ & $\begin{array}{l}\text { n.t. } \dagger \\
\text { n.t. } \\
56 \\
48\end{array}$ & $\begin{array}{l}43 \\
50 \\
40 \\
35\end{array}$ & $\begin{array}{l}51 \\
\text { n.t. } \\
\text { n.t. } \\
\text { n.t. }\end{array}$ \\
\hline Kidney & 1 & $\begin{array}{l}34 \\
\text { n.t. }\end{array}$ & $\begin{array}{l}19 \\
21\end{array}$ & $\begin{array}{l}27 \\
\text { n.t. }\end{array}$ \\
\hline & $\begin{array}{l}2 \\
3\end{array}$ & $\begin{array}{l}42 \\
26\end{array}$ & $\begin{array}{l}20 \\
20\end{array}$ & $\begin{array}{l}\text { n.t. } \\
22\end{array}$ \\
\hline Chick embryo fibroblasts & 1 & 51 & 37 & n.t. \\
\hline
\end{tabular}

\section{DISCUSSION}

The apparent lack of tissue specificity found in the present work should not be surprising since the two cell types are derived from the same animal. Since cellular DNA's exhibit species specificity rather than organ specificity, it is quite reasonable to postulate induction of the same interferon from kidney and lung cells, assuming that identical genetic information is possessed by each kind of cell. Statistical analysis performed on slopes of dose-response curves for both interferons revealed no significant deviation from parallelism. These results further indicate that the same interferon is induced in both systems.

The differences between the lung and kidney cultures might be explained by the differences in the proportions of fibroblast and epithelium-like cells in each culture. It is possible that the fibroblast cells were protected by less interferon and produced more interferon than epithelium-like cells. Thus, it is possible that some genetic information, presumably coded in all cells, cannot be as efficiently utilized by all cells.

Variation in sensitivity to interferon in different cells from the same embryo should be further considered. The sensitivity of cultures made from 10 to 11-day embryos (CEF) was intermediate to that found for the lung and kidney cultures. Procedures for the establishment of primary cell cultures vary in different laboratories (e.g. age of embryo, medium composition, trypsinization procedures) and it is possible that these differences will result in a variation in the ability of different cell types to survive and to become established. Furthermore, cells of various types may have a selective advantage under the cultural conditions imposed and populations may consequently change with time. It is possible that the sigmoid nature of the dose-response curve (Lindenmann \& Gifford, 1963b) may be due, in part, to the presence of a cell type which is relatively insensitive to the action of interferon. 
The findings presented in the present paper also have implications for the possible therapeutic use of interferon, since different kinds of cells from the same animal may show variability in their response to interferon. Consideration should therefore be given not only to the interferon sensitivity of a given virus, but also to the interferon sensitivity of the cell type in which the virus replicates. The sensitivity of a virus in an in vitro assay may not indicate the efficacy of interferon treatment in vivo, since the cell types in which the virus replicates in these two instances may differ. Also, the sensitivity to interferon exhibited by cells in culture may differ from the sensitivity of the same cell type in tissue.

This investigation was supported by research grant AI-04361 and training grant AI-0128 of the National Institute of Allergy and Infectious Diseases, National Institutes of Health, United States Public Health Service.

\section{REFERENCES}

Gifford, G. E., Mussett, M. V. \& Heller, E. (1964). Comparative studies on the production and assay of interferon. J. gen. Microbiol. 34, 475 .

Ho, M. (1964). Identification and 'induction' of interferon. Bact. Rev. 28, 367.

LINDENMANN, J. \& GifFoRd, G. E. (1963a). Studies on vaccinia virus plaque formation and its inhibition by interferon. I. Dynamics of plaque formation by vaccinia virus. Virology 19, 283.

LindenManN, J. \& GifFord, G. E. (1963 b). Studies on vaccinia virus plaque formation and its inhibition by interferon. III. A simplified plaque inhibition assay of interferon. Virology 19, 302.

TyrReLl, D. A. J. (1959). Interferon produced by cultures of calf kidney cells. Nature, Lond. 184, 452. 